\title{
СТАБИЛЬНОСТЬ ПОЗИТИВНОГО И ЕСТЕСТВЕННОГО ПРАВА
}

\section{STABILITY OF POSITIVE AND NATURAL LAW}

\section{Usenkov}

Summary. The subject of research is the stability of positive and natural law. The author makes an attempt to determine whether positive law tends to stability or dynamism to a greater extent by examining in this context the properties of rights that are traditionally distinguished in the scientific literature and are inherent to it. It is concluded that positive law has a unique combination of stability and dynamism for the social system, which is inherent in it in a dualistic balance. Also, according to the results of the study of natural law, the conclusion is formulated that it tends to be more stable than positive law, due to a number of essential characteristics.

Keywords: stability, dynamism, signs of law, properties of systems, normative generalizations, oxymoron of legal stability, natural law, positive law.

\author{
Усенков Иван Алексеевич \\ Аспирант, Волгоградский государственный \\ университет \\ i.usenkov@volsu.ru
}

Аннотация. Предметом исследования является стабильность позитивного и естественного права. Автором предпринимается попытка установить, к стабильности или динамизму в большей степени тяготеет позитивное право, путем исследования в данном контексте традиционно выделяемых В научной литературе свойств прав, имманентно ему присущих. Сделан вывод о том, что позитивное право обладает уникальным для социальной системы сочетанием стабильности и динамизма, имманентно присущих ему в дуалистическом равновесии. Также по результатам исследования естественного права сформулирован вывод 0 том, что более тяготеет к стабильности, чем позитивное право, в силу ряда сущностных характеристик.

Ключевые слова: стабильность, динамизм, признаки права, свойства систем, нормативные обобщения, оксюморон правовой стабильности, естественное право, позитивное право.

О.Е. Кутафина, В.В. Лапаевой, Р.3. Лившица, Н.П. Медведева, С.В. Полениной, В.А. Рыбакова, В.М. Савицкого, Ю.А. Тихомирова, В.А. Туманова, Т.Я. Хабриевой и других. С.С. Алексеев, несмотря на отсутствие специальных работ по данной тематике, неоднократно затрагивал проблематику стабильности и динамизма позитивного и естественного права, и внес в нее свой значительный вклад.

Позитивное право, обладая рядом ключевых признаков, в первую очередь, представляет собой «систему (упорядоченную совокупность) норм» или «нормативную систему». Системный характер права во многом предопределяет его тяготение к стабильности, так как все закономерности систем так или иначе расположены к приданию им определенной степени устойчивости.

Первым из таких свойств является эмерджентность, предполагающая наличие у системы большего количества свойств, чем у отдельных его элементов, пусть и взятых в аналогичной совокупности. Переплетающиеся связи правовых институтов делают систему права органичной и эффективной, в то же время обуславливая болезненность сколь бы то ни было существенных изменений в отдельных ее областях. Нарушение целостности и отработанного порядка функционирования системы вызывает ее сопротивление в виде частичной утраты сверхаддитивного эффекта. 
Обособленность системы от окружающего мира должна существенно влиять на ее стабильность. Однако к праву нельзя в полной мере применить данное свойство: как система, функционирующая в обществе, оно открыто для взаимодействия с политикой, социумом и другими сферами общественной жизни. Иное нивелировало бы ценность права, исключило бы возможность для него отвечать на меняющиеся запросы общества, быть релевантным повестке дня.

Но все же, как справедливо отмечал профессор Алексеев, право достаточно обособлено от общества, догматично, достаточно ориентировано на сохранение данности существующих отношений, чтобы самому по себе являться механизмом реализации и поддержания устойчивости и стабильности социума [1, С. 56]. То есть, пусть право и не изолировано полностью от общества и испытывает влияние с его стороны, в конечном счете, оно настолько отстранено от него, что обладает стабильностью выше обычной для социальных систем, и в силу этого выполняет функцию стабилизации самого общества.

Право, безусловно, обладает присущей системам иерархичностью. При этом система права неопределенно-иерархична, то есть большие ее элементы расчленяются на более мелкие, лучше поддающиеся исследованию и оценке. Однако даже подобная иерархичность благотворно отражается на стабильности системы: при необходимости изменение нижестоящего элемента в иерархии позволяет сохранить вышестоящий элемент практически в неизменном виде. Таким образом, системный характер права априорно влечет за собой его тяготение к стабильности.

Однако сущность права не исчерпывается его определением как системы, в связи с чем на предмет стабильности необходимо рассмотреть его сигнатурные свойства, выделяемые С. С. Алексеевым, в частности

1. нормативность (общеобязательная нормативность);

2. определенность содержания (формальная определенность);

3. государственная обеспеченность (гарантированность) [2, С. 37].

Последнее из перечисленных качеств определенно стабилизирует право. «Строгость российских законов компенсируется необязательностью их исполнения»,писал М.Е. Салтыков-Щедрин. Действительно, можно сколько угодно ужесточать законодательство либо вносить в него иные изменения, если их действительная реализация не гарантирована властью государства. С другой стороны, в государстве, тщательно контролирующим исполнение собственных законов, не допустим волюнта- ризм в их принятии. В таком случае обязательно наличие структурированного и логически обоснованного стадийного законотворческого процесса, исключающего возможность принятия нормативно-правовых актов, реализация которых с помощью властных институтов государства негативно сказалась бы на регулируемых общественных отношениях.

При этом стоит отметить, что, гарантируя исполнение законов, государство управомочено своей волей их принимать и отменять их действие, тем самым способствуя динамизму права. Конечно, правотворческий процесс предполагает под собой сложную борьбу политических сил общества, которые порой аннигилируют стремления друг друга, но подобная ситуация, в конечном итоге, вредит всему обществу, в связи с чем создаются правовые (sic!) механизмы разрешения подобных казусов.

Обычно называемое в научной литературе свойство права «формальная определённость», обозначенная С.С. Алексеевым более корректным по своему смыслу термином «определенность содержания права», в различных коннотациях, но одинаково гарантированно стабилизирует право как систему [1, С. 49].

Формальная определенность права в наиболее распространенном ее понимании предполагает акцент именно на писанном, закрепленном в нормативных актах, прецеденте и т.п., внешнем виде правовых норм. Соответственно, внесение правок в них должно отвечать установленной процедуре. В то же время предельно точная, развернутая и формализованная структура нормативно-правовых документов повышает определенность содержания правовых норм и позволяет элиминировать частые изменения в праве, имеющие целью изменение или дополнение несовершенных правовых предписаний.

Таким образом, каким бы ни был акцент при рассмотрении формальной определённости как одного из ключевых свойств права, его влияние на стабильность последнего положительно.

Завершающим из приведенных качеств права является его нормативность. Данное свойство предполагает распространение действия правовых предписаний на всех без исключения субъектов, все явления и процессы в определенном государстве.

В первую очередь, нормативность права позволяет ему деятельно влиять на сверхсистему - все общество, упорядочивая и стабилизируя его, равным образом устанавливая нормы для всех акторов правового пространства. Влияние нормативности на стабильность и динамизм самого права далеко не столь очевидно. 
Проявляется оно уже в более отдаленной взаимосвязи, корреспондируя важности нормативно-правовых предписаний федерального уровня, распространяющихся на всю территорию страны. В частности, порядок принятия ненормативного правового акта в сравнении с законами существенно упрощен. Таким образом, нормативность права влияет на его стабильность не непосредственно, а через особую значимость тех правовых предписаний, которые распространяют свое действие на неопределенный круг субъектов.

По результатам рассмотрения ключевых свойств права, необходимо констатировать, что по своей сущности оно тяготеет как к стабильности (через некоторые свойства права как системы: эмерджентность, иерархичность; через формальную определенность, нормативность и гарантированность), так и к динамизму (через открытость права как системы, волевой характер права). Таким образом, то что С.С. Алексеев называл совмещением несовместимого в живой и одновременно жесткой материи права, является не просто эмпирическим наблюдением, а жестко детерминировано сущностью и внутренними качествами права как феномена общественной жизни [1, С. 304].

Право вынуждено являться сдерживающим аберрации общественного развития, пароксизмы сиюминутной политической, экономической и социальной обстановки устойчивым и стабилизирующим институтом и в то же самое время следовать за непрерывно развивающейся жизнью, в любой момент времени рискуя либо устареть и остаться неприменимым к реальности рудиментом, либо стать инструментом, обслуживающим интересы отдельных социальных групп, властных изменять его своей волей.

Механизмы разрешения этого оксюморона правовой стабильности вырабатывались на протяжении всей истории развития права. Одним из таковых являются нормативные обобщения, присущие правовым системам романо-германской правовой семьи.

Возникая и повторяясь в жизни общества, некоторые ситуации («сущее») должны получать свое правовое разрешение. Обобщением опыта наиболее оптимального разрешения подобных ситуаций является норма права («должное»). Закрепление обобщений высокого уровня не только создает ситуацию правовой определенности, но и стабилизирует право путем содержащегося в них потенциала для решения более широкого спектра вариаций общественных отношений, чем тот, который явился основанием для конструирования самой нормы. Сами по себе правовые предписания в определенных условиях становятся воплощенной в жизни реальностью. В итоге описанный дуализм («сущее» как основа «должного» и «должное» как фактор «сущего») в своем равновесном состоянии способен обеспечивать «совмещение несовместимого» в праве.

Однако, несмотря на то, что выше речь шла почти исключительно о позитивном праве, нельзя не остановиться на стабильности естественного права. Понимая под естественным правом сумму требований, по своей исходной основе непосредственно, без какого-либо прямого людского участия рожденных самой натуральной жизнью общества, «природой», «естеством» человеческого бытия, объективными условиями жизнедеятельности, естественным ходом вещей, С.С. Алексеев не только предопределяет его неразрывную связь и взаимодействие с правом позитивным, но и ставит перед нами достаточно сложный вопрос о стабильности естественного права [3, С. 29].

Не выполняя функций позитивного права, естественное право также стремится в мир «должного», пусть и представляя собой долженствование второго порядка, преимущественно выраженное социальных регуляторах, отличных от императивно-властной системы позитивного права. Тем не менее, в некоторых случаях идеи естественного права находят если не прямое закрепление, то отражение в нормах позитивного права.

Естественное право куда стабильнее позитивного, в нем не так ярко выражена тенденция к динамизму. Обусловлено это следующими его чертами:

1. Историчность. Многие естественные права формировались веками и существовали на протяжении тысячелетий либо были выстраданы человечеством через множество терний.

2. Общий характер. Предельная степень обобщений естественных прав усложняет их толкование и применение, но практически гарантирует их незыблемость.

3. Долженствование второго порядка. Как уже отмечалось, естественное право стремится к своему становлению как должного, но его не умаляет существование в «неправовых» формах, в связи с чем оно невосприимчиво к признанию его тем или иным государством, формулировке, закреплённой очередным правотворческим органом, или реформе законодательства.

Поэтому присущий естественному праву динамизм ограничен невысокой скоростью изменения фундаментальных принципов общественных отношений. Уникальное сочетание стабильности и динамизма нашло свое отражение в теории естественного права с исторически меняющимся содержанием, согласно которой последнее включает в себя имплицитно присущее требование справедливости (стабильное и вечное) и соответствую- 
щее приспособление права к ценностям общества и эпохи (динамичная составляющая).

Позитивное право обладает уникальным для социальной системы сочетанием стабильности и динамизма, имманентно присущих ему в дуалистическом равновесии, которое обеспечивается в правовых системах романо-германского типа в том числе нормативными обобщениями, представляющими собой круговорот реальности и права как сущего и должного. Естественное право как право, устанавливающее долженствования второго порядка, тяготеет к стабильности в силу ряда сущностных характеристик, но тем не менее спорадически способно проявлять динамические свойства.

\section{ЛИТЕРАТУРА}

1. Восхождение к праву. Поиски и решения / С. С. Алексеев. М.: НОРМА, 2001. 752 С.

2. Право: азбука, теория, философия. Опыт комплексного исследования / С. С. Алексеев. М.: Статут, 1999. 712 с.

3. Философия права / С. С. Алексеев. М.: НОРМА, 1997. 336 с.

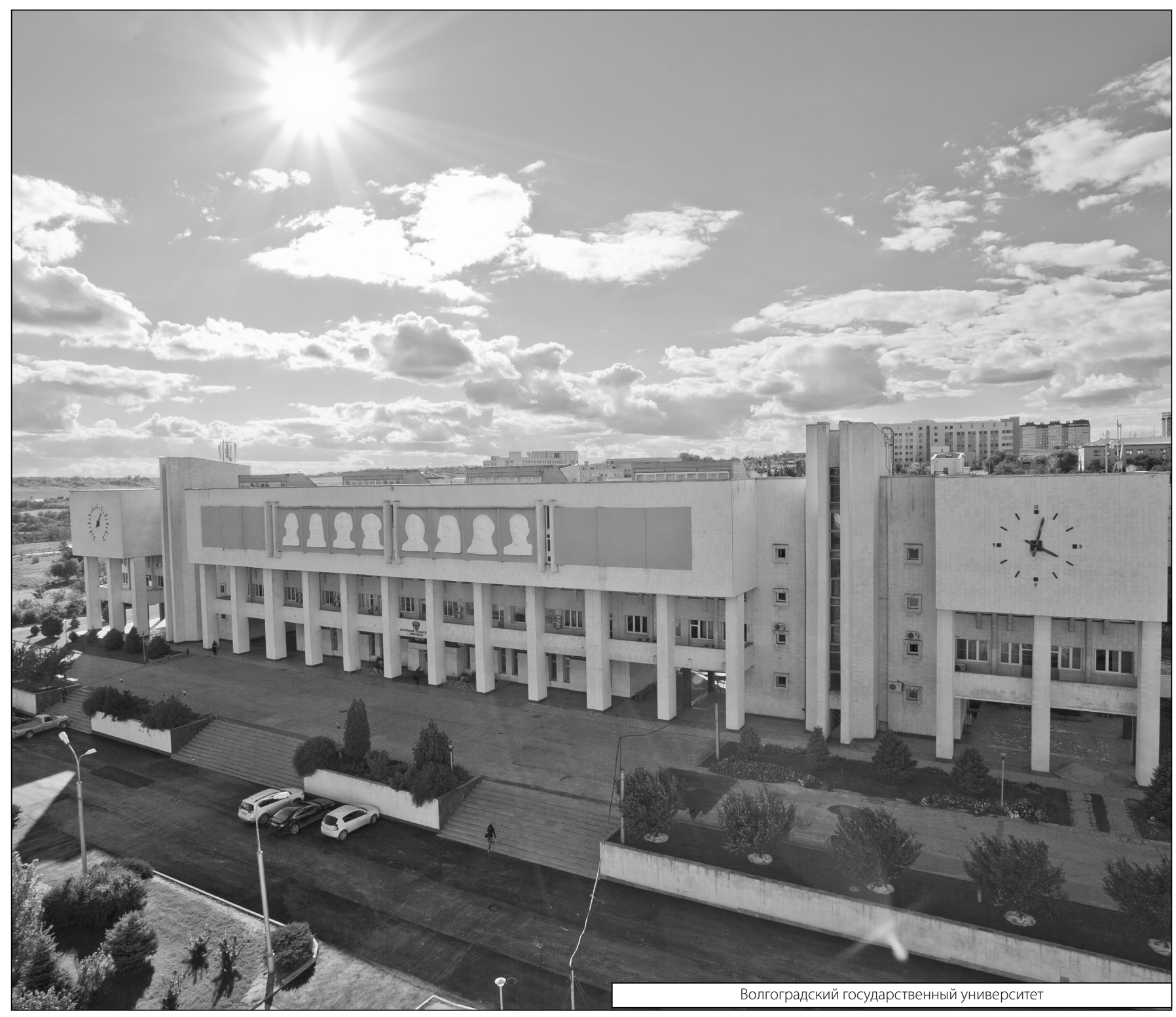

